\title{
Screening for chronic respiratory diseases in Georgia
}

\author{
D. Gorecka, J. Zieliński
}

Monaldi Arch Chest Dis 2009; 71: 4, 139-140.

Department of Respiratory Medicine, Institute of Tuberculosis and Lung Diseases, Warsaw, Poland.

Correspondence: Prof. Dorota Gorecka, Department of Respiratory Medicine, Institute of Tuberculosis and Lung Diseases, ul.Plocka 26,01-138Warsaw,Poland; e-mail:d.gorecka@igichp.edu.pl

Chronic respiratory diseases are an important cause of morbidity and mortality worldwide. Tuberculosis is responsible for 2 million deaths annually, COPD for another 3 million with an ever increasing trend. It is estimated that COPD will be the third most important cause of all deaths in 2020 and the fifth most important cause of DALY's. COPD, asthma and chronic rhinitis are important causes of morbidity resulting in high costs to society, both direct medical costs and indirect social costs.

The World Health Organisation makes estimation in relation to mortality and morbidity in every country relying on available, usually official data. There is however, a general lack of epidemiological studies in most of the countries in Central and Eastern Europe and countries that formed the previous Soviet Union.

Global Alliance against Respiratory Disease (GARD), a recently created an organization under the auspices of $\mathrm{WHO}$, is promoting recognition of the importance of respiratory diseases worldwide and is also collecting available data on the prevalence of chronic respiratory diseases [1].

The study by Chkhaidze et al in the current issue of Monaldi Archives of Chest Diseases [2] was performed in the scope of GARD initiatives. It is an important contribution trying to present real life prevalence of chronic respiratory diseases in Georgia.

The study they have undertaken is a pilot study of two health districts near the capital Tibilisi comprising approximately 70.000 population. A physician's administered questionnaire was applied to patients $5+$ years old attending primary health care centres. It requested information on the physician's diagnosis of tuberculosis, asthma and symptoms of asthma, chronic bronchitis, allergy and allergic rhinitis. In a sample of patients with symptoms of chronic cough and sputum of three years duration spirometry was performed. Additional questions assessed demographics, smoking status, occupational exposures and respiratory infections (pneumonia) in the past. The results of the study were compared to official statistics on the aforementioned diseases.

A total of 3646 patients were studied, $41 \%$ were males, $15 \%$ were aged between 5-14. Most of the patients had secondary school education. A to- tal of 733 patients were ever smokers, 712 men and 24 women.

Asthma was diagnosed in $4.8 \%$, tuberculosis in $2 \%$, chronic cough in $20 \%$, COPD in $7 \%$, allergic rhinitis in 4\%. Among 92 patients with chronic cough and phlegm in whom spirometry was performed COPD was diagnosed in 62 (67\%). The prevalence of asthma, tuberculosis, allergic rhinitis complied with official data on these diseases. Incidence (notification) rate of tuberculosis is high, similarly to majority of former Soviet Union countries except the Baltic states [3].

However, government data on COPD grossly underestimated the prevalence of this disease. The most detailed part of survey concerned COPD. All subjects reporting symptoms of chronic bronchitis, complying with the current definition of the disease were subjected to post bronchodilator spirometry. Almost all were more than 40 years of age. The signs of not completely reversible obstruction was found in $24 \%$ of them. This is very high figure most probably influenced by the fact that a highly selected population was studied, i.e. a population with a very high probability of the disease [4]. Interestingly, frequency of different stages of COPD in the Chkhaidze study was very close to that found in a family physician setting in Poland [5]. Vast majority of subjects had mild or moderate stage of the disease. Georgian study supports the idea of spirometric screening for COPD in population of high risk for COPD to prevent progression of COPD to severe stage [6].

The prevalence of smoking was low (20\%) in the population studied. Among the total population $14+$ years the prevalence of tobacco smoking was $24 \%$. One has to note that the prevalence among men was $48 \%$ and among women $0,01 \%$. According to The Tobacco Atlas the prevalence of smoking in Soviet Union satellite countries was 50-60\% in males and less than $20 \%$ in females [7]. The study has several limitations. It was not an epidemiological study, but an assessment of diagnosis of patients attending their primary care physicians. No data on occupational exposure was presented.

Countries of Central and Eastern Europe and Central Asia that, since the end of the second World War or since 1918, were separated from the free world present with much higher mortality rates than 
high income countries. First 10 years of transition in health care systems in those countries (1990-2000) did not show signs of closing the gap $[8,9]$.

It is our view that health organisations responsible for global world health should focus more on these countries sharing the western world experience in conducting proper epidemiological studies and helping to introduce preventive measures to non communicable diseases and helping to control tuberculosis [10].

\section{References}

1. Global surveillance, prevention and control of chronic respiratory diseases. A comprehensive approach. WHO 2007; 69-76.

2. Chkhaidze I, Maglakelidze T, Khaltaev N. Chronic respiratory diseases at primary health care level in Georgia: the results of the pilot study. Monaldi Arch Chest Dis 2009; 71: 141-146.

3. Tuberculosis surveillance in Europe World Health Organization, 2007.
4. Buist AS, McBurni MA, Vollmer WM, et al. on behalf of the BOLD Collaborative Research Group. International variation in the prevalence of COPD (The BOLD Study): a population-based prevalence study. Lancet 2007; 370: 741-750.

5. Bednarek M, Maciejewski J, Wozniak M, Kuca P, Zielinski J. Prevalence, severity and underdiagnosis of COPD in the primary care setting. Thorax 2008; 63: 402-407.

6. Soriano JB, Zielinski J, Price D. Screening for and early detection of chronic obstructive pulmonary disease. Lancet 2009; 347: 721-731.

7. Shafey O, Eriksen M, Ross H, Mackay J. The Tobacco Atlas. 3rd edition, American Cancer Society 2009.

8. Lopez A, Mathers CD, Ezzati M, Jamison DT, Murray CJ. Global and regional burden of disease and risk factors, 2001: systematic analysis of population health data. Lancet 2006; 367: 1747-1757.

9. Rechel B, McKee M. Health reform in central and eastern Europe and the former Soviet Union. Lancet 2009; 374: 1186-1195.

10. Marx FM, Skachkova EI, Son IM, et al. Control of tuberculosis in Russia and other countries of the former Soviet Union. Pneumonologie 2009; 63: 253-260.

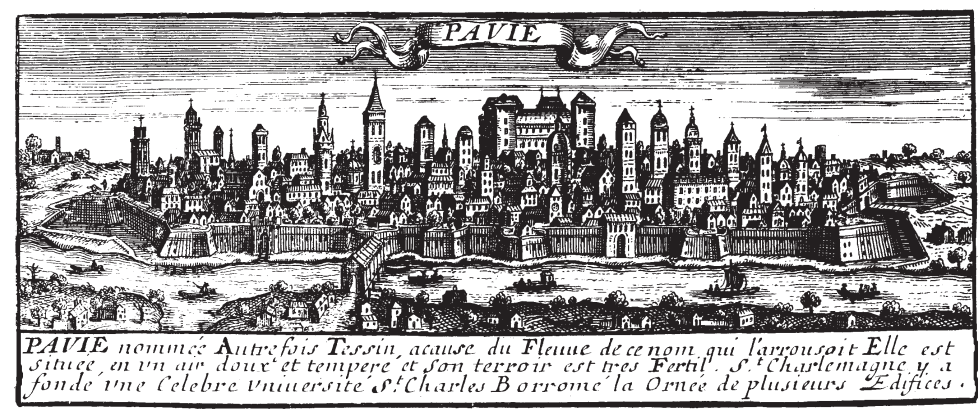

